\title{
Foreword
}

\section{Malignant Pleural \\ Mesothelioma: An Insidious \\ Disease}

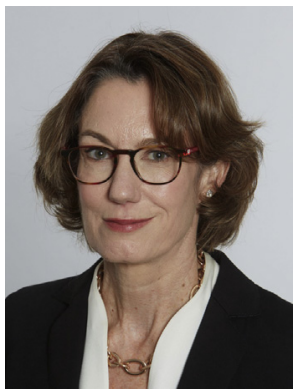

Virginia R. Litle, MD

Consulting Editor

We are excited to bring you this focused issue for the Thoracic Surgery Clinics on "Malignant Pleural Mesothelioma," an insidious disease with a projected rise in incidence secondary to environmental factors, including the World Trade Center tragedy, which transpired almost 20 years ago. Our previous issue on this topic was appropriately guest edited by the legendary $\mathrm{Dr}$ David Sugarbaker in the inaugural year when Chest Surgery Clinics was renamed Thoracic Surgery Clinics in 2004. After many advances in the field, including molecular characterization of the tumor, identification of potential biomarkers, and controversies about surgical and multimodality management, a current report was indeed indicated!

As mentored by Dr Sugarbaker from postgraduate training to his leadership position at Baylor, Dr Bryan M. Burt follows in the footsteps of this surgical giant to bring together some of the experts in this field so we may stay abreast of clinical and translational advances in the management of mesothelioma. In the words of one of Dr Sugarbaker's many trainees, we must maintain a "focused attention and clarity of purpose," especially when pursuing and evolving through this increasingly complex world of academic and clinical surgery. Wise words to move our specialty forward and to benefit our patients.

Thank you to our contributors and to guest editor, Dr Burt. May he continue in the footsteps of a thoracic giant-to advance the area of mesothelioma management but also to inspire intellectual curiosity in future generations of thoracic surgeons. We hope you will enjoy this issue!

Virginia R. Litle, MD Division of Thoracic Surgery Department of Surgery Boston University

88 East Newton Street Collamore Building, Suite 7380 Boston, MA 02118, USA

E-mail address: Virginia.litle@bmc.org Twitter: @vlitlemd (V.R. Litle) 